\title{
ОСОБЕННОСТИ ПОДГОТОВКИ УПРАВЛЕНЧЕСКИХ КАДРОВ В СФЕРЕ ЗДРАВООХРАНЕНИЯ
}

\section{(c) 2019 Халтурин Роман Александрович}

кандидат экономических наук, заведующий кафедрой экономического анализа и прогнозирования Московский государственный медико-стоматологический университет имени А.И. Евдокимова Министерства здравоохранения Российской Федерации, Москва E-mail: xalturin86@mail.ru

В данной статье рассмотрены некоторые особенности подготовки управленческих кадров, присущие для сферы здравоохранения. Отмечается важность качественной подготовки медицинского персонала и высококвалифицированных управленческих кадров, от деятельности которых будет зависеть состояние охраны и укрепления здоровья населения нашей страны. Эффективное использование ресурсов невозможно без компетентных руководителей, которые способны решать актуальные цели и задачи, поставленные в отрасли.

Ключевые слова: менеджмент, медицинские организации, здравоохранение, управленческие кадры, главный врач, образование, медицина, лидерство.

Подготовка управленческих кадров является одной из главных целей сферы здравоохранения. В Стратегии развития здравоохранения в РФ на период до 2025 г. отмечена необходимость совершенствования системы медицинского образования и кадрового обеспечения [1]. В данном контексте это также подтверждают национальный проект «Здравоохранение», «Концепция долгосрочного развития РФ на период до 2020 года», Федеральный закон «Об образовании в Российской Федерации».

Здравоохранение - это сфера, одна из нескольких уникальных по количеству и вовлеченности в нее человек. С Древнего мира здравоохранение является той сферой, которая объединила правителей и простых смертных, богачей и бедняков, детей и взрослых. На врачей возложена почетная миссия - лечить людей, а на главных врачей медицинских организаций руководить всем процессом, начиная от взятия в руки пациентом телефона до выстраивания стратегии и видения организации. В современном мире главных врачей мы можем называть менеджерами, хотя то, что они делают, вряд ли можно назвать менеджментом. Правильнее говорить о лидерстве. Люди, руководящие человеческими жизнями, по-настоящему необычны. Они работают, как с выдающимися профессорами и заслуженными врачами, так и осуществляют рутинную техническую работу, или принимают пациента «с улицы», они все делают для успеха своей медицинской организации, и, в конечном счете, для здоровья и счастья миллионов людей. В свою очередь, эти люди пристально наблюдают за их деятельностью, каждый их шаг беспощадно анализируется и бурно обсуждается. Здравоохранение не просто отражает проблемы, оно помещает их под увеличительное стекло, это следствие внимания со стороны пациентов. В здравоохранении вы все равно, что проводите каждый день общие собрания акционеров, на которых присутствуют тысячи человек.

Наиболее важной задачей медицины на всех этапах ее развития является ориентация на общие цели, этические нормы, соблюдение морали, способствующие достижению эффективных результатов, сохранение жизни и здоровья общества нашей страны. Целью деятельности медицинского сотрудника является результат доступности и качество медицинской помощи.

Управление медицинской организацией требует особого подхода ввиду специфичности выпускаемого на рынок продукта - медицинской услуги. Социальная значимость медицинского бизнеса диктует применение особых методов менеджмента. Работу главных врачей и врачей ежедневно изучают, критикуют, хвалят и высмеивают миллионы. Некоторым пациентам кажется, что они могли бы справиться куда лучше, если бы они обладали такими же знаниями и обучались большое количество лет, а в сферах здравоохранения и образования, действительно надо пройти большой путь, чтобы занять одну из руководящих должностей (путь от абитури- 
ента до доктора наук займет порядка 20 лет).

В то время как в современных компаниях рассуждают о коллективном управлении, менеджменте качества и проектном менеджменте, большинство организаций здравоохранения России продолжает трудиться по модели Тейлора, придерживаясь жесткой субординации. Поэтому, несмотря на модные лозунги, в части управления кадрами, медицинские организации остаются устаревшими, в основном в них принимаются решения лишь на уровне главных врачей, а информация поступает сверху вниз. В такой ситуации сотрудникам сложно высказывать свои идеи, а недовольство и возражения остаются неуслышанными.

Роль главного врача в медицинской клинике привлекательна, но невероятна сложна. Люди думают, что все сводится к покупке оборудования и подбору персонала. На самом же деле главный врач должен создавать обстановку для эффективной работы медицинской организации, оправдать огромные ожидания пациентов, разрешить все проблемы, справляться с оказываемым на него давлением и оставаться сосредоточенным на выполнении важных задач, а к этому надо добавить, что главные врачи обычно еще и практикуют - это еще одна из отличительных особенностей двух сфер (здравоохранение и образование). Тяжело представить себе, что директор завода встанет за станок на производстве. Главным врачам приходится принимать то, что они теперь не просто оказывают медицинскую помощь пациентам, но и разрабатывают эффективную модель управления сотрудниками и координируют их действия, выстраивают всю работу клиники на долгосрочную перспективу. Только таким образом может продолжаться развитие медицинской организации. В результате возникает вопрос о важности наличия специального образования в сфере менеджмента у высшего медицинского персонала.

Продолжая выделять особенности в управления в здравоохранении, стоит отметить, что вокруг главных врачей крутится огромное количество влиятельных людей. Это чиновники, врачи других клиник, пациенты, поставщики оборудования, «селебрити», СМИ и др. Масштабное участие в здравоохранении людей «высшего уровня» поддерживает его, поэтому влияние этих людей необходимо, но они же создают проблему для главных врачей. В бизнесе их называют стейкхолдерами, но мы их можем назвать заинтере- сованными лицами, в данном случае, применительно к здравоохранению. Если перенестись на 50-70 лет назад, то мы также увидим чиновников, пациентов, прессу и общественность. Руководящие органы, медицинские ассоциации и союзы также имели место для существования, но сегодня изменились степень и рычаги их влияния, находящиеся в распоряжении.

Главный врач государственной больницы зависит от людей, распределяющих бюджеты, т.е. он не обладает достаточной властью, а в прямой зависимости от государственных служащих, которые к тому же могут снять с должности. Другие стейкхолдеры также стали по-своему намного влиятельнее, раньше общественность, чье воздействие ограничивалось разговорами дома, оказывает серьезное давление посредством социальных медиа, или пресса, которая могла стоять на страже медицинских стандартов, теперь в состоянии ускорить отставку главного врача.

На главных врачей оказывается тяжелое и многоаспектное давление. Никогда еще сосредоточенность, самоконтроль, умение справиться с давлением и быстро восстанавливаться не были так важны.

Все эти особенности еще раз подчеркивают важность получения специального образования по менеджменту. Профессиональная подготовка управленческих кадров в сфере здравоохранения предполагает освоение основных образовательных программ, в которых определены виды деятельности, компетенции, знания, умения и организационно-методическое обеспечение образовательного процесса, что позволяет обратить особое внимание на необходимость формирования готовности к трудовой деятельности, будущего бакалавра или магистра по направлению «Менеджмент». Стратегическое направление экономического и социального развития нашей страны на современном этапе требует новых высококвалифицированных субъектов профессиональной деятельности.

В этой связи, руководителям сферы здравоохранения, предстоит найти ответ на значимый вопрос: продолжить ли использование сложившегося десятилетиями подхода к управлению персоналом, предполагающего адаптацию системы управления к хронической нехватке человеческих ресурсов в медицинских организациях, и обеспечивать достижение соответствия фактического трудового потенциала требуемому за счет совместительства и интенсификации 
труда врачей, или расширить функциональную зону персонал-менеджмента, самостоятельно стимулируя предложение труда за счет обучения и выпуска в ВУЗах менеджеров в сфере здравоохранения [2].

В современных условиях управление медицинскими организациями предполагает трансформацию функций высшего звена в управленческие, руководство уже не может оставаться просто врачами, а должны владеть всем арсеналом средств менеджмента. Занимая руководящую должность, человек, по сути, перестает быть врачом, а становится менеджером здравоохранения - наемным профессиональным управляющим, в его деятельности экономические и управленческие знания должны занимать ведущее место. Необходимы навыки грамотного управления кадровыми, финансовыми и материальными ресурсами медицинской организации.

Итак, главный врач должен обеспечить стабильность, работать, как следует и, как и в большинстве медицинских организаций, вести свой коллектив к эффективному функционированию. Лидерство редко сводится к героическим посылам и лозунгам, гораздо важнее уметь придать уверенность, вдохновить, показать преданность людям, т.к. их ответная реакция распространяется, в первую очередь, на вас. У каждого главного врача, как и у любого другого лидера, свой стиль. Отношения между главным врачом и его заместителем могут иметь разный характер, они могут меняться от обстановки. Очевидно лишь то, что успешный главный врач назначит компетентного заместителя, который будет ему соответствовать, а успешный заместитель направит свою энергию на то, чтобы эти отношения приносили пользу клинике.

Также стоит обратить внимание на сотрудников частной медицинской организации и выделить еще особенность для руководителей таких клиник. Есть два типа врачей: одни приносят все, что у них есть (включая наработанную годами базу пациентов), на благо клиники, стремясь сделать ее лучше, другие используют организацию, чтобы выглядеть самим как можно лучше (переманивая пациентов у своих же коллег). Имея дело со вторым типом, который еще надо выявить, крайне важно задействовать навыки общения для того, чтобы убедить их в неверности выбранного пути. Человеку, работа- ющему в окружении такого количества заинтересованных лиц, просто необходимы отличные навыки общения.

В заключении перейдем к отношениям главного врача и пациентов. Медицинские организации по проходимости можно сравнивать с английскими футбольными стадионами, их посещают тысячи в неделю. В России заболеваемость населения по основным классам болезней в 2017 г. составила 114382 тыс. человек [3], поэтому пациенты - это основа всей деятельности медицинской организации. Главный врач не должен находиться в центре внимания пациентов, потому что там должны быть врачи и медсестры. Пациенты понимают, что для работы с медицинской организацией нужен главный врач, но в большинстве случаев они приходят не к нему. Одна из пагубных ловушек главных врачей - возомнить себя «центром клиники». Пациенты оказывают давление, воодушевляют, они те, для кого работают главные врачи. Их слишком много, чтобы говорить с каждым лично, но они могут оказывать серьезное влияние на карьеру главного врача, особенно если он молод и не обладает компетенциями менеджера. В современном мире лидеры среди управленческого состава медицинских клиник, стараются наладить контакт с большим количеством пациентов, они считают это удовольствием, а не обязанностью.

Управление медицинской организацией предполагает два качества: способность отстраниться, посмотреть «с высоты» и способность взять на себя ответственность за результаты подчиненных. Руководитель берет на себя не только свои ошибки, но и ошибки своих сотрудников, необходимо действовать, организуя их, управляя их рабочим временем, деятельностью и результатами. Только сфокусировавшись на «завтрашнем дне», можно продемонстрировать свои управленческие способности: предвосхищать грядущие изменения, управлять потенциальными конфликтами, стимулировать активность сотрудников, демонстрировать лидерские качества и др. Руководить - это обеспечивать выполнение сегодня, но при этом размышлять, как сделать завтра. Это значит думать иначе, чтобы действовать иначе, руководствуясь при этом главным принципом в сфере здравоохранения: первым делом - удовлетворение нужд пациентов. 


\section{Библиографический список}

1. Указ Президента РФ от 6 июня 2019 г. N254 «О Стратегии развития здравоохранения в Российской Федерации на период до 2025 года».

2. Иванов Н.П., Малкина Л.В. HR-Маркетинг в системе менеджмента современной медицинской организации // Фундаментальные исследования. - 2017.- № 10-2.- С. 351-357.

3. Российский статистический ежегодник. 2018: Стат.сб. / Росстат.- М., 2018, С. 212. 